Psychological distress in the labour market: Shame or deprivation?

\author{
Authors: Peter A Creed \\ School of Applied Psychology - Gold Coast and Service \\ Industry Research Centre, Griffith University \\ Juanita Muller \\ School of Applied Psychology - Gold Coast and Work, \\ Leisure and Community Research Centre, Griffith University
}

Contact: Assoc Prof Peter A Creed

School of Applied Psychology

Griffith University - Gold Coast

PMB 50 GCMC

Gold Coast, Queensland Australia 9726

Telephone: +61 755528810

Facsimile: +61755528291

Email: $\quad$ p.creed@griffith.edu.au 


\title{
Psychological distress in the labour market: Shame or deprivation?
}

\begin{abstract}
This study examined the relative efficacy of two environmental/job characteristic models (financial hardship/shaming and deprivation) that have been proposed to account for the negative well-being effects for people in the labour market. A sample of 258 labour market participants, comprising 125 unemployed and 133 full-time employed individuals, were administered scales tapping well-being, financial distress, shame and the latent benefits of employment (social support, collective purpose, activity, time structure, status). Consistent with prediction, the unemployed sample had poorer well-being, more shame and financial distress, and had less access to all latent benefits, except for social support. Inconsistent with both the financial hardship/shaming and deprivation models, shame accounted for a modest amount of variance in well-being, and only one latent variable (status) was a significant individual predictor. Social support and activity did not mediate the effects of shame and financial distress on well-being, and shame did not interact with financial distress to predict well-being, as expected. Financial distress was the most important and consistent predictor of well-being, which is best explained by agency restriction models, rather than the two models tested. Implications for explaining well-being in labour market participants are highlighted.
\end{abstract}

Keywords: shame, deprivation, financial distress, latent benefits of employment 
There is consistent evidence that psychological well-being for participants in the labour market is related to their level of access to the latent and manifest benefits of employment (Creed \& Macintyre, 2001; Warr, 1999). Jahoda (1981) proposed a latent deprivation approach to understanding psychological well-being for those in the work force. She argued that people have five primary needs that are met through their contact with paid employment. These latent benefits relate to their need for social support outside of the immediate family, the need for a structure to one's day, the need to engage in meaningful activities, the need to be a part of a collective purpose with group goals, and the need for status or personal identity. Jahoda maintained that people engaged in paid employment for the manifest benefits it provides (benefits associated with material gains, mainly income) but that while employed also benefited psychologically from having their five primary (or latent) needs met. Jahoda and others (e.g., see Haworth, 1997) have used this account to explain why psychological well-being declines when people lose their jobs or are underemployed. The theory proposes that when people lose their jobs or are underemployed they are deprived of both manifest and latent benefits of employment, but it is the loss or deprivation of the latent benefits that operates to reduce psychological well-being.

Whereas Jahoda's latent deprivation model has been used primarily to explain the decline in psychological well-being experienced when people lose their job, it has parallels with other environmental models that have been proposed to explain psychological well-being for people in employment. Chief amongst these employment related models are the job characteristics model (Hackman \& Oldham, 1980), the demand-control-support model (Karasek \& Theorell, 1990), and Warr's (1987, 1999) vitamin model. All of these models, including Jahoda's, implicate job characteristics or environmental features as important in determining well-being. Karasek and Thorell, for example, focus on the three job characteristics of task demands, decision latitude and 
social support, while Warr identified ten environmental features important for well-being. Many of Warr's characteristics overlap with Jahoda's, but include specific additional propositions such as physical safety, supervisor support, and opportunity for control.

Studies testing Jahoda's model have found differences between employed and unemployed samples (Evans \& Haworth, 1991) and between unemployed and underemployed samples (Creed \& Machin, 2002) on measures of the five latent benefits. For example, when the latent benefits have been tested individually, unemployed people, when contrasted with employed people or the general population, have been found to have less structured and purposeful use of time (Jackson, 1999; Wanberg, Griffiths, \& Gavin, 1997), to be less active (Underlid, 1996), to be involved in fewer social activities (Underlid), to have less social support from close relations and authority figures (Jackson, 1999), to feel less involved and to have fewer common goals (Evans \& Haworth, 1991; Haworth \& Ducker, 1991), and to perceive having a lower status (Evans \& Haworth, 1991). Access to these latent benefits has also been shown to be positively related to wellbeing (Creed \& Macintyre, 2001; Evans \& Haworth, 1991; Haworth \& Ducker, 1991; Kilpatrick \& Trew, 1985; Waters \& Muller, 2003; Winefield, Tiggemann \& Winefield, 1992).

Despite Jahoda's, and the other environmental models' focus on the benefits of access to latent job characteristics, it has been shown that deprivation of the manifest benefits of employment (i.e., income) has a clear detrimental effect on well-being. For example, Kokko and Pulkkinen (1997) in a study comparing employed and unemployed samples found that unemployed people experienced more financial deprivation and were more distressed. Dew, Bromet and Penkower (1992) found an association between financial difficulties and depression in a sample of unemployed women, and a similar link has been reported for unemployed people in general (Vinokur, Price \& Caplan, 1991). Using a large-scale Irish national database, Whelan (1992) examined both subjective experiences 
of financial strain and objective material deprivation in a large cohort of unemployed individuals. Whelan concluded that poverty, construed by these two broad variables, played a substantial role in mediating the effects of unemployment for both the individual involved and the person's family. In an attempt to account for the effect of financial distress, Fryer (1986) argued that financial distress reduces the individual's capacity to plan a meaningful future, operates to restrict personal agency, and consequentially contributes to a decline in psychological well-being.

The evidence from these studies is that access to the latent and manifest benefits of employment varies across occupational status, and that access to the latent and manifest benefits is associated with well-being, with those having less access having lowered levels of psychological well-being.

Recently, it has been proposed (Rantakeisa, Starrin \& Hagquist, 1999) that the negative psychological effects of unemployment may be explained by the level of financial distress experienced by unemployed people in combination with the shame associated with joblessness. In this context, shame is viewed as the product of strained social interactions (Scheff, 1990). It is argued that people strive to interact and feel affinity with others. They do this largely by striving to meet accepted common standards and ideals, in this case to fulfill the social convention of being usefully employed. When these ideals cannot be met the individual feels humiliated and degraded in the eyes of others. There is a long history in Western cultures of viewing work as an honourable activity (Crawford, 1984), with paid employment having both a financial and a moral dimension. Paid employment allows individuals to fulfill their financial needs, and through this to meet societal standards and expectations. Further, earning money through an exchange of labour is itself a "legitimate social role" (Rantakeisa et al., p. 878). Unemployment then not only produces financial deprivation and restricts people from engaging in a socially acceptable lifestyle, but it deprives them of one of the most 
important social roles, that of worker. Living off others, whether it is from social security or family, does not have the same social value as living off one's own earnings.

There are early reports in the descriptive literature of shame being associated with unemployment (e.g., Bakke, 1933; Eisenberg \& Lazarsfeld, 1938). Evidence for a connection been psychological distress and shame has been reported by Eales (1989) who, in a qualitative study using a small sample of unemployed men, found that $25 \%$ of the sample reported shame, and that shame was correlated with financial distress and the presence of negative moods. Second, Rantakeisa et al., using a large-scale survey of unemployed young people, found that $42 \%$ of their sample reported shaming experiences, and that shaming was associated with gender (higher incidence in males) and length of unemployment (more shaming the longer unemployed). Shaming was also associated with poorer mental well-being and health variables, reduced spare-time activities, and reduced contact with friends. Shaming and financial distress interaction effects were found for well-being, activity and social support, with the most severe deficits found in young males with the highest financial strain and the most shaming experiences.

As there has been no examination of the impact of shame on well-being in the wider labour market, the present study will test a number of propositions related to Rantakeisa et al's. financial hardship/shaming model with a large heterogeneous labour market sample that included both employed and unemployed individuals. If paid employment can be conceptualised as an honourable activity, and unemployment as shameful, then those who are unemployed are expected to report higher levels of shame than those employed. Rantakeisa et al. argued that financial distress and shame influenced psychological wellbeing by reducing activity and social support. If this is the case, activity and social support is expected to act as mediators between financial hardship/shaming and wellbeing. As the financial hardship/shaming model has also been proposed as an alternate model for explaining well-being for labour market participants, this study will examine 
the level of well-being accounted for by each model (deprivation and financial hardship/shaming) and test the relative contributions of each model to the prediction of well-being.

\section{Method}

\section{Participants}

A total of 266 surveys were administered. Eight surveys were discarded because of missing data, which left 258 participants in the study. These 258 participants comprised two groups: (1) 125 unemployed individuals with a mean age of 29.25 years $(S D=9.51)$, made up of 88 males $(70 \%)$ and 37 females $(30 \%)$, who had been out of work on average for 40.47 weeks $(S D=63.40$, Range $=1-263$ weeks); (2) 133 full-time employed individuals with a mean age of $32.71(S D=11.50)$, made up of 94 males $(71 \%)$ and 39 females (29\%), who were working on average 41.31 hours per week $(S D=6.86$, Range $=$ 30-62 hours). At the time of the survey, the unemployed sample was utilising the national employment registry office and all were in receipt of government sponsored employment welfare. The employed participants were drawn from businesses operating in the same locality as the national employment registry office.

\section{Measures}

Psychological Distress. The 12-item version of the General Health Questionnaire (Goldberg, 1972) was utilised as a global measure of psychological distress. This version has been widely used and recommended for use as a screening device in occupational settings (e.g., Warr, 1987). Respondents were asked to report on how they felt recently on a range of variables, including cognitive processing, self esteem, anxiety and depression, for example, "Have you recently been able to concentrate on whatever you're doing?". Responses were scored on a four-point scale ranging from zero to three using anchors such as "better than usual/same as usual/less than usual/much more than usual". Higher scores indicate greater psychological distress. Goldberg and Williams (1988) reported a 
mean internal consistency of .85 . In the present study, the internal reliability coefficient was .83 .

Latent Benefits of Employment. Five subscales from the Latent and Manifest Benefits scale (Muller, Creed, Waters, \& Machin, 2000) were used to measure the five latent benefits of time structure, social support, collective purpose, status, and activity. Respondents were asked to indicate the strength of their agreement to bipolar statements on five 6-item subscales. Sample items were, "Time usually drags for me/Time rarely drags for me" (time structure), "I regularly do things with other people/I rarely do things with other people" (social support), "I usually feel a part of the community/I rarely feel a part of the community" (collective purpose), "What I do is important/What I do is not important" (status), and "I usually have a lot of things to do/I rarely have a lot of things to do" (activity). Higher scores indicate more access to the latent benefits. Muller et al. report sound initial reliability and validity data, with internal reliabilities ranging from .75-.88. The internal reliability coefficients for the present study were .88 (time structure), .94 (social support), .90 (collective purpose), .88 (status) and .91 (activity).

Shame. This construct was measured by the 10-item Shame scale (Harder \& Zalma, 1990). Respondents were asked to indicate how frequently they experienced shameful feelings on a 4-point response format with end-points of "you never experience the feeling" to "you experience the feeling continuously or almost continuously". Sample items were, "embarrassed" and "humiliated". Higher scores represent more shame. Harder and Zalma reported an internal reliability of .78 in their study; in the present study this was .82 .

Financial Distress. The financial distress subscale from the Latent and Manifest Benefits scale (Muller et al., 2000) was used to measure this construct. Respondents were asked to indicate the strength of their agreement to bipolar statements on a 6-item scale. A sample item was, "I can usually live on the money I receive/I usually have trouble living 
on the money I receive". Higher scores indicate more financial distress. Muller et al. report sound initial scale properties, including an internal reliability coefficient of .91; in the present study this was .96 .

\section{Procedure}

The study was cross-sectional, with participants being two samples from the southeastern corner of Queensland, Australia. Unemployed participants were approached to complete a survey as they were utilising the national employment registry office. Employed participants were approached via their employers at their place of work. All surveys contained the preceding scales and questions related to age, gender, length of unemployment (unemployed sample) and number of hours worked (employed sample).

\section{Results}

\section{Validity of study measures}

To test the construct validity and independence of the scales used in the study, the 58 items from the General Health Questionnaire (12 items), the Latent and Manifest Benefits subscales of Time Structure (6), Social Support (6), Collective Purpose (6), Status (6), Activity (6), and Financial Strain (6), and the Shame scale (10) were included in a principal axis factor analysis, using a direct oblimin rotation. The Kaiser-Meyer-Olkin Measure of Sampling Adequacy (.89) and Bartlett's Test of Sphericity $(p<.001)$ indicated the suitability of the data for factor analysis (Tabachnik \& Fidell, 1996). Eight factors were rotated (to reflect the eight scales included). This solution was factorially simple and interpretable. All items loaded on their respective factors, and only one item had a cross-loading of $>.30(.32)$. Thus, all 58 items were retained in their respective scales. 
Differences between Employed and Unemployed Groups

A between subjects MANOVA was used to test whether the unemployed sample reported higher levels of shame, psychological distress and access to the latent and manifest benefits of employment than the employed sample. In this analysis, Shame, Psychological Distress, Time Structure, Social Support, Collective Purpose, Activity, Status and Financial Distress were included as the dependent variables. The independent variables were gender (male and female) and group (unemployed and employed). Age was initially included as a covariate, but as no significant effect was found for this variable, the results for the MANOVA are reported. Significant multivariate results were obtained for the main effect of group, $F(8,243)=38.59, p<.001$, but not for gender or the group by gender interaction. At the univariate level, significant effects $(p<.05 / 8$, i.e., $p<.006)$ were obtained for all dependent variables $(p<.001)$ apart from Social Support, with the unemployed sample reporting more Shame, Psychological Distress and Financial Strain, and less access to the latent benefits of Time Structure, Collective Purpose, Status, and Activity. Summary data for this analysis are reported in Table 1; bivariate correlations are reported in Table 2. 
Table 1

Sample size, means and standard deviations for employed, unemployed and total samples for Shame, Psychological Distress, Time Structure, Social Support, Collective Purpose, Status, Activity and Financial Distress

\begin{tabular}{|c|c|c|c|c|c|c|c|c|c|c|c|c|c|c|c|c|c|c|}
\hline \multirow[b]{3}{*}{ Variable } & \multicolumn{6}{|c|}{ Employed } & \multicolumn{6}{|c|}{ Unemployed } & \multicolumn{6}{|c|}{ Total } \\
\hline & \multicolumn{2}{|c|}{$\begin{array}{c}\text { Males } \\
n=93\end{array}$} & \multicolumn{2}{|c|}{$\begin{array}{c}\text { Females } \\
n=39\end{array}$} & \multicolumn{2}{|c|}{$\begin{array}{c}\text { Total } \\
n=132\end{array}$} & \multicolumn{2}{|c|}{$\begin{array}{l}\text { Males } \\
n=86\end{array}$} & \multicolumn{2}{|c|}{$\begin{array}{c}\text { Females } \\
n=36\end{array}$} & \multicolumn{2}{|c|}{$\begin{array}{c}\text { Total } \\
n=122\end{array}$} & \multicolumn{2}{|c|}{$\begin{array}{c}\text { Males } \\
n=179\end{array}$} & \multicolumn{2}{|c|}{$\begin{array}{c}\text { Females } \\
n=75\end{array}$} & \multicolumn{2}{|c|}{$\begin{array}{l}\text { Sample } \\
n=254\end{array}$} \\
\hline & $M$ & $S D$ & $M$ & $S D$ & $M$ & $S D$ & $M$ & $S D$ & $M$ & $S D$ & $M$ & $S D$ & $M$ & $S D$ & $M$ & $S D$ & $M$ & $S D$ \\
\hline Shame & 14.85 & 3.66 & 15.82 & 5.03 & 15.14 & 4.11 & 18.35 & 5.03 & 18.69 & 4.52 & 18.45 & 4.87 & 16.53 & 4.70 & 17.20 & 4.93 & 16.73 & 4.78 \\
\hline Psychological Distress & 14.30 & 5.11 & 14.38 & 6.29 & 14.33 & 5.46 & 17.66 & 5.85 & 19.75 & 6.48 & 18.28 & 6.09 & 15.92 & 5.72 & 16.96 & 6.89 & 16.22 & 6.09 \\
\hline Time Structure & 35.19 & 5.34 & 33.85 & 7.93 & 34.80 & 6.22 & 25.02 & 8.05 & 23.33 & 6.96 & 24.52 & 7.75 & 30.31 & 8.46 & 28.80 & 9.12 & 29.86 & 8.67 \\
\hline Social Support & 26.96 & 9.11 & 27.77 & 8.72 & 27.20 & 8.97 & 25.29 & 9.83 & 21.42 & 9.79 & 24.15 & 9.94 & 26.16 & 9.47 & 24.72 & 9.73 & 25.73 & 9.55 \\
\hline Collective Purpose & 26.66 & 7.64 & 24.74 & 9.22 & 26.09 & 8.15 & 21.83 & 9.13 & 20.17 & 7.48 & 21.34 & 8.68 & 24.34 & 8.71 & 22.55 & 8.69 & 23.81 & 8.72 \\
\hline Status & 33.31 & 4.64 & 33.77 & 5.79 & 33.44 & 4.99 & 30.66 & 7.29 & 29.78 & 7.79 & 30.40 & 7.42 & 32.04 & 6.19 & 31.84 & 7.06 & 31.98 & 6.44 \\
\hline Activity & 35.57 & 5.20 & 35.38 & 5.68 & 35.52 & 5.33 & 28.14 & 7.67 & 26.19 & 7.39 & 27.57 & 7.62 & 32.00 & 7.48 & 30.97 & 7.99 & 31.70 & 7.63 \\
\hline Financial Distress & 18.74 & 8.89 & 17.03 & 9.58 & 18.23 & 9.10 & 33.43 & 8.92 & 34.19 & 8.26 & 33.66 & 8.71 & 25.80 & 11.54 & 25.27 & 12.41 & 25.64 & 11.78 \\
\hline
\end{tabular}


Table 2

Bivariate correlations for Psychological Distress, Shame, Time Structure, Social Support, Collective Purpose, Status, Activity, Financial Distress, Gender, Age, Hours Worked (employed sample) and Weeks Unemployed (unemployed sample)

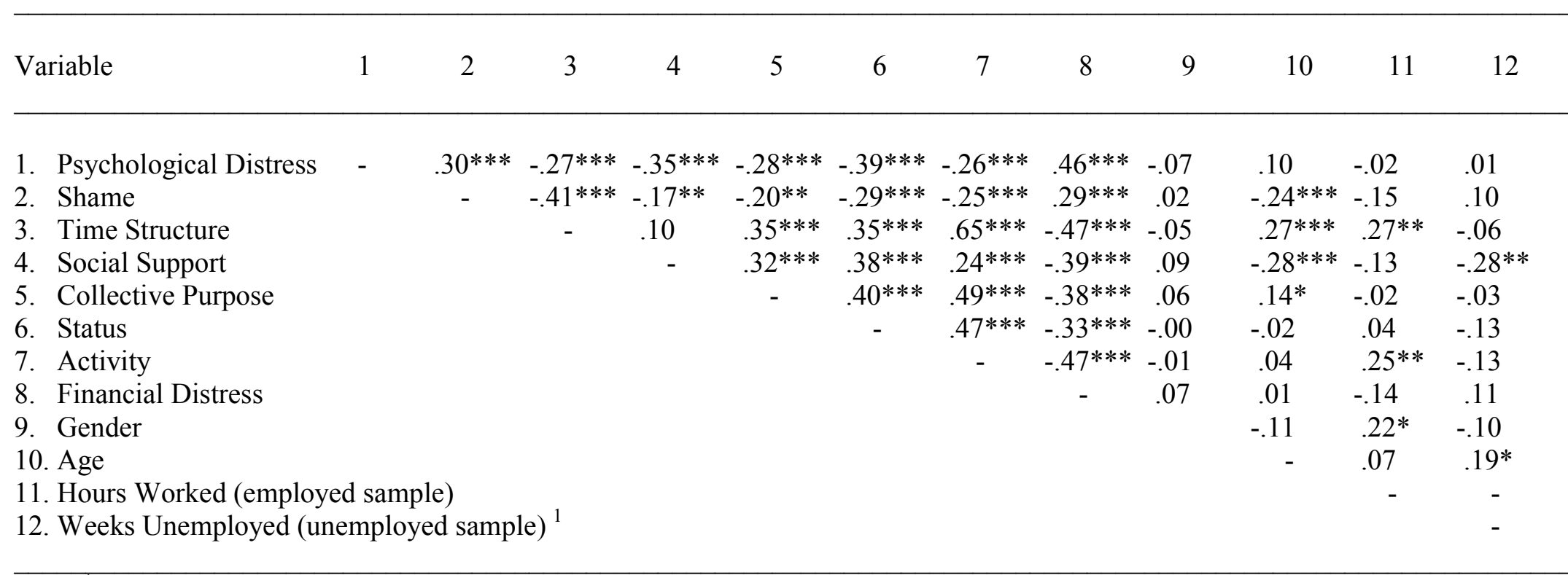

Note: ${ }^{1}=$ Log10 transformation used to normalise variable. $*=p<.05 ; * *=p<.01 ; * * *=p<.001$. 


\section{Predicting Psychological Distress}

To determine the amount of variance accounted for independently by the financial hardship/shaming model and the deprivation model, two hierarchical multiple regression analyses were conducted. The first analysis regressed Psychological Distress on the financial hardship/shaming variables; the second regressed Psychological Distress on the deprivation variables. In the first analysis, Age, Gender and Group were entered at Step 1, Financial Distress and Shame were entered at Step 2, and a Financial Distress by Shame interaction term was entered at Step 3. In the second analysis, Age, Gender and Group were entered at Step 1, Time Structure, Social Support, Collective Purpose, Status and Activity were entered at Step 2, and Financial Distress was entered at Step 3. Dummy variables were created for Gender (baseline $=$ Female) and Group (baseline = Unemployed). To avoid multicollinearity problems with the interaction variable, this variable was created using centred deviation scores (Aiken \& West, 1991).

For the financial hardship/shaming model, Age, Gender and Group (Model 1) were able to significantly predict Psychological Distress, $F(3,250)=13.21, p<.001$, and account for $13.7 \%$ of the variance. The variables to make significant individual contributions, in order of importance, were Group and Age, with more distress being associated with being unemployed and older. The addition of Financial Distress and Shame led to a significant increase in $R^{2}, F(2,248)=22.32, p<.001$, a significantly fitting model, $F(5,248)=18.21, p<.001($ Model 2$)$, and accounted for a total of $26.9 \%$ of the variance. In this model, the variables to make significant individual contributions were, in order of importance, Financial Distress, Shame and Age. The addition of the Financial Distress by Shame interaction term did not add significantly to $R^{2}(p=.97)$. This model (Model 3) remained significantly fitting, $F(6,247)=15.11, p<.001$, and accounted for a total of $26.9 \%$ of the variance. The variables to make significant 
individual contributions were, in order of importance, Financial Distress, Shame and Age. See Table 3 for summary of analysis.

For the deprivation model, Age, Gender and Group (Model 1) were able to significantly predict Psychological Distress, $F(3,254)=13.61, p<.001$, and account for $13.9 \%$ of the variance. The variables to make significant individual contributions were, in order of importance, Group and Age, with more distress being associated with being unemployed and older. The addition of the latent variables of Time Structure, Social Support, Collective Purpose, Status and Activity led to a significant increase in $R^{2}, F(5$, $249)=9.08, p<.001$, a significantly fitting model, $F(8,249)=11.59, p<.001($ Model 2), and accounted for a total of $27.1 \%$ of the variance. The variables to make significant individual contributions were, in order of importance, Status, Time Structure and Social Support. The addition of Financial Distress led to a further significant increase in $R^{2}, F(1$, $248)=13.74, p<.001$, a significantly fitting model, $F(9,248)=12.36, p<.001$ (Model 3 ), and accounted for a total of $31 \%$ of the variance. In this model, the variables to make significant individual contributions were, in order of importance, Status and Financial Distress. See Table 3.

The financial hardship/shaming model accounted for a total of $26.9 \%$ of the variance in Psychological Distress, while the latent deprivation model accounted for a total of $31 \%$. Steiger's (1980) $z$ test indicated that there was no significant difference $(p>.05)$ between the two sets of independent variables in predicting this dependent variable.

\section{Relative contributions of Financial hardship/shaming and Deprivation variables}

To determine the relative amount of variance accounted for by the financial hardship/shaming and deprivation model variables, a further hierarchical regression analysis was conducted. In this analysis, Psychological Distress was regressed on all 
financial hardship/shaming variables and latent deprivation variables. Age, Gender and Group were entered at Step 1, and Financial Distress, Shame, the Financial Distress by Shame interaction term, Time Structure, Social Support, Collective Purpose, Status and Activity were entered at Step 2. Again, dummy variables were created for Gender $($ baseline $=$ Female $)$ and Group $($ baseline $=$ Unemployed $)$.

In this analysis, Age, Gender and Group (Model 1) were able to significantly predict Psychological Distress, $F(3,250)=13.21, p<.001$, and account for $13.7 \%$ of the variance. The variables to make significant individual contributions were, in order of importance, Group and Age. The addition of the financial hardship/shaming and latent variables led to a significant increase in $R^{2}, F(8,242)=8.36, p<.001$, a significantly fitting model, $F(11,242)=10.53, p<.001($ Model 2$)$, and accounted for a total of $32.4 \%$ of the variance. The variables to make significant individual contributions were, in order of importance, Financial Distress, Status, Shame and Age. See Table 3. 
Table 3

Summary of hierarchical multiple regression analyses for variables predicting Psychological Distress

\begin{tabular}{|c|c|c|c|c|c|}
\hline Variable & $B$ & $S E B$ & $\beta$ & $R^{2} \Delta$ & $R^{2}$ \\
\hline \multicolumn{6}{|l|}{ Financial hardship/shaming } \\
\hline Step 1 & & & & 13.7 & 13.7 \\
\hline Age & .08 & .03 & $.15^{*}$ & & \\
\hline Gender & -1.02 & .71 & -.08 & & \\
\hline Group & -.44 & .92 & -.04 & & \\
\hline Step 2 & & & & 13.2 & 26.9 \\
\hline Financial Distress & .20 & .04 & $.38 * * *$ & & \\
\hline Shame & .27 & .08 & $.21 * *$ & & \\
\hline Step 3 & & & & 00.0 & 26.9 \\
\hline Financial Distress x Shame & .00 & .01 & -.00 & & \\
\hline \multicolumn{6}{|l|}{ Latent Deprivation } \\
\hline Step 1 & & & & 13.9 & 13.9 \\
\hline Age & .05 & .03 & .09 & & \\
\hline Gender & -1.00 & .69 & -.08 & & \\
\hline Group & -1.30 & .95 & -.11 & & \\
\hline Step 2 & & & & 13.3 & 27.1 \\
\hline Time Structure & -.05 & .06 & -.07 & & \\
\hline Social Support & -.06 & .04 & -.10 & & \\
\hline Collective Purpose & -.04 & .05 & -.06 & & \\
\hline Status & -.23 & .06 & $-.25 * * *$ & & \\
\hline Activity & .11 & .06 & .14 & & \\
\hline Step 3 & & & & 3.8 & 31.0 \\
\hline Financial Distress & .15 & .04 & $.29 * * *$ & & \\
\hline \multicolumn{6}{|l|}{ Total } \\
\hline Step 1 & & & & 13.7 & 13.7 \\
\hline Age & .07 & .04 & $.12 *$ & & \\
\hline Gender & -.92 & .69 & -.07 & & \\
\hline Group & -.97 & .98 & -.08 & & \\
\hline Step 2 & & & & 18.7 & 32.4 \\
\hline Financial Distress & .15 & .04 & $.28 * * *$ & & \\
\hline Shame & .20 & .08 & $.16^{*}$ & & \\
\hline Financial Distress $x$ Shame & -.00 & .01 & -.02 & & \\
\hline Time Structure & -.02 & .06 & -.03 & & \\
\hline Social Support & -.05 & .04 & -.08 & & \\
\hline Collective Purpose & -.05 & .05 & -.07 & & \\
\hline Status & -.21 & .06 & $-.22 * *$ & & \\
\hline Activity & .10 & .07 & .12 & & \\
\hline
\end{tabular}

Note: $*=p<.05 ; * *=p<.01 ; * * *=p<.001$. 
Activity and Social Support as Mediators

A path analysis was constructed to test whether Financial Distress and Shame influenced Psychological Distress through Activity and Social Support. Path analysis does not set out to prove causality among a set of variables but it is able to investigate how tenable a particular model is. This analysis involved performing separate multiple regression equations for each endogenous variable in the model and calculating direct and indirect effects for the predictor variables on Psychological Distress. The standardised regression coefficients of the predictor variables and their endogenous (dependent) variables are displayed as path coefficients (beta weights). Table 4 presents the direct, indirect and total effects for each predictor variable for each endogenous variable. The results indicate that $27 \%$ of the variance of Psychological Distress was accounted for by the variables of Financial Distress, Shame, Financial Distress x Shame, Social Support and Activity. Financial Distress, Shame and Social Support were significant individual predictors. Financial Distress had the strongest total effect (beta $=.40$ ), followed in importance by Social Support (-.19) and Shame (.17). Financial Distress x Shame and Activity had no significant effect on Psychological Distress. Financial Distress, Shame and Financial Distress x Shame significantly predicted Social Support, accounting for $16 \%$ of the variance; Financial Distress was the only significant individual predictor (.36). Financial Distress, Shame and Financial Distress x Shame significantly predicted Activity, accounting for $24 \%$ of the variance. Financial Distress (-.43) was the only significant individual predictor. The evidence from this analysis is that Psychological Distress was primary determined directly by Financial Distress, Social Support and Shame, and indirectly by Financial Distress through Social Support. There was no support for a direct or mediational role for Activity. Social Support was a mediator for Financial Distress but not for Shame. Significant pathways are reported in Figure 1. 
Table 4

Direct and indirect effects for predicting Psychological Distress using Financial Distress, Shame, Financial Distress $x$ Shame, Social Support and Activity

\begin{tabular}{|c|c|c|c|c|c|}
\hline $\begin{array}{l}\text { Outcome } \\
\text { variables }\end{array}$ & $\begin{array}{l}\text { Predictor } \\
\text { variables }\end{array}$ & $\begin{array}{l}\text { Direct } \\
\text { effects }\end{array}$ & $\begin{array}{l}\text { Indirect } \\
\text { effects }\end{array}$ & $\begin{array}{l}\text { Total } \\
\text { effects }\end{array}$ & $R^{2}$ \\
\hline \multirow[t]{5}{*}{ Psychological Distress } & Financial Distress & $.33 * * *$ & .07 & .40 & \multirow[t]{5}{*}{$.27 * * *$} \\
\hline & Shame & $.17 * *$ & .00 & .17 & \\
\hline & Financial distress $\mathrm{x}$ Shame & .01 & .00 & .01 & \\
\hline & Social Support & $-.19 * *$ & - & -.19 & \\
\hline & Activity & -.02 & - & .02 & \\
\hline \multirow[t]{3}{*}{ Social Support } & Financial Distress & $-.36 * * *$ & - & -.36 & \multirow[t]{3}{*}{$.16^{* * * *}$} \\
\hline & Shame & -.04 & - & -.04 & \\
\hline & Financial distress $\mathrm{x}$ Shame & -.08 & - & -.08 & \\
\hline \multirow[t]{3}{*}{ Activity } & Financial Distress & $-.43 * * *$ & - & -.43 & \multirow[t]{3}{*}{$.24 * * *$} \\
\hline & Shame & -.11 & - & -.11 & \\
\hline & Financial distress $\mathrm{x}$ Shame & -.04 & - & -.04 & \\
\hline
\end{tabular}

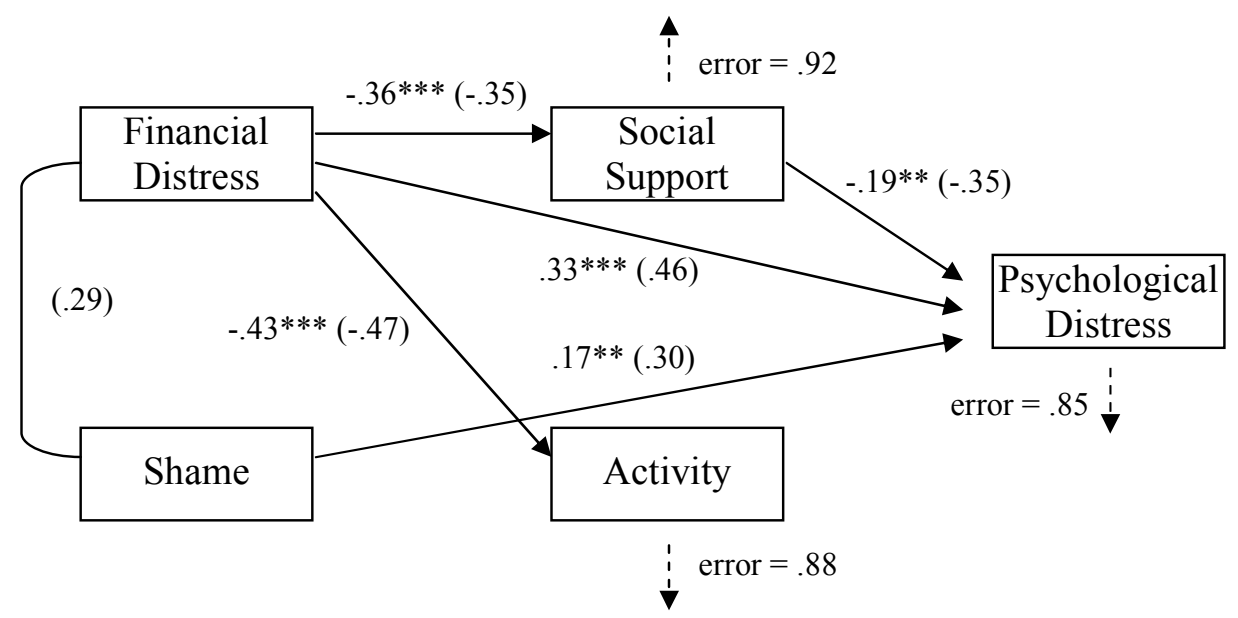

Figure 1: Significant pathways for effects of Financial Distress, Shame and Financial Distress x Shame on Psychological Distress. Standardised regression coefficients are presented without brackets, bivariate correlations are presented within brackets. $* *=p<$ $.01 ; * * *=p<.001$ 


\section{Discussion}

First, the evidence from this study is that shame was independent of psychological distress and the latent and manifest benefits of employment, meaning that shame was not merely a proxy for well-being or one of the variables from the latent deprivation model, and could be tested for its independent effect on well-being. Unlike the findings of Rantakeisa et al., who tested unemployed people alone, the current study, which utilised a more heterogeneous labour market sample, did not find that shame was associated with gender. Shame was also not associated with the length of unemployment for the unemployed sample, nor with the number of hours worked with the employed sample. This is inconsistent with the financial hardship/shaming model, which predicts that shame should be greater for the longer unemployed as they experience the greatest discrepancy between situation and societal expectations. Conversely, the model would also predict that working longer hours should result in more pride (i.e., less shame) resulting from greater concordance between situation and normative expectations. Neither of the expected outcomes was found in this study.

There were significant differences between the employed and unemployed samples on levels of shame, with, as predicted, the unemployed group reporting more shaming experiences. There were also significant differences between the two groups on four of the five latent benefits (Time Structure, Status, Collective Purpose and Activity), Financial Distress and Psychological Distress, in the expected directions. The two groups did not differ on Social Support. It can be said that the unemployed group was disadvantaged when compared to the employed group by having less access to most of the latent benefits, experiencing more financial distress and shame, and reporting lower psychological well-being. These results are consistent with the general literature on job loss. However, a caveat does need to be added here. While considerable effort was made 
to include unemployed and employed people who could be meaningfully compared, it is possible that the two groups differed in ways not measured in this study, which accounted for the differences. Unemployed samples, for example, typically have lower levels of education and training than employed people (Jackson, 1999), and future studies might consider matched samples to avoid possible systematic differences.

When the two models (financial hardship/shaming and deprivation) were compared directly, there was no significant difference between them in predicting well-being (accounting for $26.9 \%$ and $31 \%$ respectively). The most likely explanation for this nonsignificant result is the large proportion of variance accounted for by Financial Distress, and the small proportion accounted for by Shame and the latent benefit variables, even though Shame and the latent benefit variable of Status both made significant individual contributions in their respective models. When the financial hardship/shaming and deprivation variables were entered into the regression analysis together, Financial Distress remained the most important predictor, with Status and Shame maintaining significant, though more minor, individual contributions. Thus, the important variables predicting well-being were Financial Distress, Status and Shame. Lastly, there was no support for an interaction effect between Financial Distress and Shame.

Further, in relation to the financial hardship/shaming model, it was expected that Financial Distress and Shame would influence well-being through the mediators of Activity and Social Support. In the path analysis, Shame contributed directly to predicting Psychological Distress, but was not mediated via Social Support or Activity. Financial Distress again had a substantial direct effect, and contributed indirectly via Social Support, but was not mediated by Activity. Activity contributed little to the model directly or indirectly, and the Financial Distress by Shame interaction term failed to 
predict Social Support, Activity and Psychological Distress, as expected with the financial hardship/shaming model.

These results provide only modest support for the financial hardship/shaming model. Shame played a minor role in predicting well-being, and the Financial Distress by Shame interaction term did not account for any significant individual variance. Responses to unemployment have been shown to vary according to the prevailing unemployment rate in a community, with higher unemployment rates leading, for example, to less negative well-being effects (Jackson \& Warr, 1987) and lower parasuicide rates (Platt \& Kreitman, 1985). Unemployment rates in Western countries have been near-consistently high since the early 1970 s, and it is likely that the experience of unemployment is no longer perceived as the shameful event it was reported to be in earlier research.

There was also only modest support for the deprivation model. Only one of the latent benefits, that of Status, made an individual contribution. People do benefit psychologically from access to, at least, this latent variable. However, well-being was more of a function of their perception of their financial situation. Financial Distress was the most important and consistent predictor. This variable was important when explaining variance in both the financial hardship/shaming model and the deprivation model, and when the two models were collapsed together. The evidence here is that the dominant environmental/job characteristic explanation is related to perceptions of financial wellbeing. The model best able to account for this is the agency restriction model proposed by Fryer (1986), who argued that financial distress reduces people's capacity to plan and cuts them off from a meaningful future, which leads to a reduction in psychological wellbeing. Fryer also acknowledged the role that the latent benefits of employment played in mental health (Fryer \& Payne, 1984), but considered these insufficient to fully explain the deterioration in well-being. 


\section{References}

Aiken, L. \& West, S. (1991). Multiple regression: Testing and interpreting interactions. Newbury Park, CA: Sage.

Bakke, E. W. (1933). The unemployed man: A social study. London: Nisbet.

Crawford, R. (1984). A cultural account of "health": Control, release and the social body. In J. B. McKinley, Issues in the Political Economy of Health Care. London: Tavistock.

Creed, P. A., \& Machin, M. A. (2002). Access to the latent benefits of employment for unemployed and underemployed individuals. Psychological Reports, 90, 1208-1210.

Creed, P. A., \& Macintyre, S. R. (2001). The relative effects of deprivation of the latent and manifest benefits of employment on the wellbeing of unemployed people. Journal of Occupational Health Psychology, 6(4), 324-331.

Dew, M. A., Bromet, E. J., \& Penkower, L. (1992). Mental health effects of job loss in women. Psychological Medicine, 22(3), 751-764.

Eales, M. J. (1989). Shame among unemployed men. Social Science and Medicine, 28(8), 783-789.

Eisenberg, P., \& Lazarsfeld, P. F. (1938). The psychological effects of unemployment. Psychological Bulletin, 35, 358-390.

Evans, S. T., \& Haworth, J. T. (1991). Variations in personal activity, access to categories of experience and psychological well-being in unemployed young adults. Leisure Studies, 10, 249-264.

Fryer, D. (1986). Employment deprivation and personal agency during unemployment: A critical discussion of Jahoda's explanation of the psychological effects of unemployment. Social Behaviour, 1(1), 3-23. 
Fryer, D. M., \& Payne, R. L. (1984). Pro-active behaviour in unemployment: Findings and implications. Leisure Studies, 3, 273-295.

Goldberg, D. P. (1972). The Detection of Psychiatric Illness by Questionnaire. London: Oxford University Press.

Goldberg, D. P., \& Williams, P. (1988). A Users Guide to the General Health Questionnaire. Berkshire: NFER-NELSON.

Hackman, J. R., \& Oldham, G. R. (1980). Work redesign. Mass.: Addison-Wesley.

Harder, D. H., \& Zalma, A. (1990). Two promising shame and guilt scales: A construct validity comparison. Journal of Personality Assessment, 55(3 \& 4), 729-745.

Haworth, J. T. (1997). Work, leisure and well-being. London: Routledge.

Haworth, J. T., \& Ducker, J. (1991). Psychological well-being and access to categories of experience in unemployed young adults. Leisure Studies, 10, 265-274.

Jackson, P. R. \& Warr, P. B. (1987). Mental health of unemployed men in different parts of England and Wales. British Medical Journal, 295, 525.

Jackson, T. (1999). Differences in psychosocial experiences of employed, unemployed, and student samples of young adults. Journal of Psychology, 133(1), 49-60.

Jahoda, M. (1981). Work, employment and unemployment: values theories and approaches in social research. American Psychologist, 36, 184-191.

Karasek, R. A., \& Theorell, T. (1990). Healthy work: Stress, productivity and the reconstruction of working life. New York: Basic Books.

Kilpatrick, R., \& Trew, K. (1985). Life styles and psychological well-being among unemployed men in Northern Ireland. Journal of Occupational Psychology, 58, 207-216.

Kokko, K., \& Pulkkinen, L. (1997). Economical and psychological well-being of the unemployed. Psykologia, 32, 349-359. 
Muller, J., Creed, P. A., Waters, L. \& Machin, M. A. (2000). A new scale to measure the latent functions of employment. International Journal of Psychology, 35(3-4), 266.

Platt, S., \& Kreitman, N. (1985). Parasuicide and unemployment among men in Edinburgh 1968-1982. Psychological Medicine, 15, 113-123.

Rantakeisa, U., Starrin, B., \& Hagquist, C. (1999). Financial hardship and shame: A tentative model to understand the social and health effects of unemployment. British Journal of Social Work, 29, 877-901.

Scheff, T. J. (1990). Microsociology: Discourse, emotion and social structure. Chicago: University of Chicago Press.

Steiger, J. H. (1980). Tests for comparing elements of a correlation matrix. Psychological Bulletin, 87(2), 245-251.

Tabachnik, B. G, \& Fidell, L. S. (1996). Using Multivariate Statistics. New York: HarperCollins College Publishers.

Underlid, K. (1996). Activity during unemployment and mental health. Scandinavian Journal of Psychology, 37(3), 269-281.

Vinokur, A. D., Price, R. H., \& Caplan, R. D. (1991). From field experiments to program implementation. American Journal of Community Psychology, 19(4), 543-562.

Wanberg, C. R., Griffiths, R. F., \& Gavin, M. R. (1997). Time structure and unemployment: A longitudinal investigation. Journal of Occupational and Organizational Psychology, 70, 75-95.

Warr, P. B. (1987). Work, unemployment and mental health. Oxford: Oxford University Press.

Warr, P. B. (1999). Well being and the workplace. In D. Kahneman, E. Diener, \& N. Schwarz, Well-being: The foundations of hedonic psychology (pp. 312-412). New York: Russell Sage Foundation. 
Waters, L., \& Muller, J. J. (2003). Money or time? Comparing the effects of time structure and financial deprivation on the psychological distress of unemployed adults. Australian Journal of Psychology, 55(3), 166-175.

Whelan, C. T. (1992). The role of income, life style deprivation and financial strain in mediating the impact of unemployment on psychological distress: Evidence from the Republic of Ireland. Journal of Occupational and Organizational Psychology, 65, 331344.

Winefield, A. H., Tiggemann, M., \& Winefield, H. R. (1992). Spare time use and psychological well-being in employed and unemployed young people. Journal of Occupational and Organizational Psychology, 65, 307-313. 